\title{
Quantitative Assessment of Mass Flow Boundaries in Continuous Twin-screw Granulation
}

\author{
Adrian Schmidt ${ }^{\text {ab }}$, Hans de Waard ${ }^{\mathrm{b}}$, Klaus-Peter Moll ${ }^{\mathrm{b}}$, Markus Krumme ${ }^{\mathrm{b}}$, and Peter Kleinebudde ${ }^{\star a}$
}

\begin{abstract}
In pharmaceutical manufacturing, there is an increasing interest in continuous manufacturing. As an example for fast continuous processes in general of considerable complexity, this study was focussed on improving the understanding of twin-screw wet granulation. The impact of the liquid-to-solid (L/S) mass flow ratio on product quality (granules) as well as on downstream process operations (tableting) was investigated in detail. Initially two methods were used to define L/S ratio boundaries for the granulation regime in twin-screw wet granulation. It was shown that the first method, which is based on measuring the wet granule mass flow variation, can be used to define the upper L/S ratio boundary of the granulation regime. The second method, based on measuring the granule size distribution, can be used to define the lower L/S ratio boundary of the regime. Using these methods, the granulation regime for different formulations could be established. This information was then used to show that the formulation could be optimised such that the process is more robust (i.e. wider $\mathrm{L} / \mathrm{S}$ ratio boundaries for the granulation regime). Also it could be used to optimise the formulation considering further downstream processing such as drying (using as little water as possible to reduce drying efforts) or tableting (obtain granules with optimised tableting properties). Preferably, the process should be performed close to the lower L/S ratio boundary of the granulation regime. In summary, these tools enabled the quantitative establishment of granulation regime boundaries in a twin-screw wet granulation process and can be used to optimise formulation and to create a robust process. Analogies to other continuous processes in completely different applications can be conceived.
\end{abstract}

Keywords: Continuous processing · Granule size distribution · Mass flow variation - Process optimisation . Wet granulation

\section{Introduction}

Drug manufacturing, both with respect to its chemical and pharmaceutical arms of manufacturing, is widely based on batch processes. ${ }^{[1]}$ A few exceptions exist, but predominantly the manufacturing systems in terms of process definition, process control, process equipment, material handling, quality management aspects and material release into commerce rely on the concepts of batches, or more general, of discrete amounts of materials being transformed. More recently however, the pharmaceutical industry and its regulatory authorities have shown an increasing level of interest in continuous manufacturing processes..$^{[2]}$

\footnotetext{
${ }^{\star}$ Correspondence: Prof. Dr. P. Kleinebudde ${ }^{a}$ E-mail: kleinebudde@hhu.de alnstitute of Pharmaceutics and Biopharmaceutics Heinrich-Heine-University Düsseldorf Universitätsstr. 1, Build. 26.22 D-40225 Düsseldorf, Germany bNovartis Pharma AG

Novartis Campus, CH-4002 Basel
}

Generally, continuous processes in the chemical industry are not new per se. Petrochemical plants and polymer plants that need to fulfil high volume demands have been using continuous processes for decades. All of the currently known implementations of continuous processes however, are in the field of high volume-low value products, whereas the pharmaceutical industry is with very few exceptions typically operating in a high value-low volume arena while simultaneously maintaining strictest quality requirements. Unfortunately, this is paired with a high developmental risk for the product as such, due to its main performance being assessed in clinical trials. These risks have resulted in a cost-conscious and risk-averse business model and hence limited the progress in developing new manufacturing processes, such as those based on continuous processing.

However, recent interest in continuous processes on the side of health authorities is fuelled by the promise of significantly better process control and hence the ability to obtain a higher level of assurance of quality products without increasing costs. ${ }^{[3]}$ The pharmaceutical industry is responding to this with a wide initiative, covering all aspects (technical, quality, commercial) of the business. Advantages that continuous manufacturing could offer can be, amongst others, of technical nature (e.g. hazardous material handling), ${ }^{[4]}$ in-process control (e.g. application of advanced control techniques), ${ }^{[5]}$ economic benefits (e.g. small equipment and hence plant size, variable batch size, yield improvements), ${ }^{[6]}$ quality assurance benefits (e.g. better data density, meaning more data points per $\mathrm{kg}$ product), ${ }^{[5]}$ better product quality (often conforming to tighter specifications) ${ }^{[7]}$ and more flexibility in supplying in a demand-driven environment. [3c]

In this study, an example of how a continuous process can be optimised is presented. Although the example is less of chemical nature, the rationale behind the selection of relevant parameters is more widely applicable. One of the typical steps in pharmaceutical drug product manufacturing is wet granulation. Wet granulation is a powder agglomeration process, which is commonly used in pharmaceutical industry to produce a powder with improved flow properties, tablet compactability and less tendency for segregation. ${ }^{[8]}$ During wet granulation, a granulation liquid (typically water) is mixed with a dry powder. In this dry powder typically there is at least one component that dissolves in the liquid 
and acts as 'glue' to agglomerate the powder particles together. During a subsequent drying step, the water is removed and dried granules are obtained. Wet granulation processes can be performed with various types of granulation equipment, such as high shear mixers, fluidised bed granulators or twin-screw granulators. The first two types of equipment are examples of typical batch process equipment, the latter one is continuous.

The interesting aspects of twin-screw wet granulation as a study example for a continuous process are that the overall residence time in the twin-screw granulator is within a few seconds, the dissolution of the granulation liquid-soluble ingredients even faster than that and the agglomeration of the individual particles under the influence of capillary forces of the liquid instantaneous and almost irreversible. The subsequent drying process practically freezes the condition of the granulated material in the condition it leaves the twinscrew granulator and hence allows the study of inhomogeneity due to improper process conditions at the micro level as they manifest themselves in macroscopic properties such as granule particle size distribution (amount of agglomeration depends on amount of liquid in the particle). Finally, for the pharmaceutical manufacturer, these macroscopic granule quality attributes determine the final tablet quality. The microscopic unit operations in the twin-screw wet granulation are: feeding a powder material and a liquid, mixing these two phases whereby one component of the powder dissolves in the liquid phase growing viscosity thereof and finally distributing this liquid utilizing capillary forces and thus building agglomerates. The relevant kinetics control the correct sequence of these unit operations and hence the quality of the granulated product. Analogies can be found in the chemical reaction processing as well, where mixing kinetics, phase effects and reaction kinetics show significant similarities.

In continuous twin-screw wet granulation, the ratio between the mass flow rate of solids (dry powder components) and that of liquids (typically water) has to be adapted to start particle agglomeration and granule growth. A detailed understanding of the mass flow rates, their impact on the process and the resulting product quality is therefore essential. In previous studies, the impact of the total material mass flow rate has been studied intensively. ${ }^{[6 b, 9]}$ The total material mass flow rate influences the fill level in the twin-screw granulator, which in turn impacts significantly critical quality attributes of the product, such as the granule size distribution and porosity.

Another critical process parameter in twin-screw wet granulation is the liq- uid-to-solid (L/S) mass flow ratio. It has been described that the L/S ratio has an impact on granule critical quality attributes such as granule size distribution. ${ }^{[10]}$ It was found that at low L/S ratios, granules were relatively small with a few larger lumps among them. With increasing L/S ratios, a reduction of the amount of fines, as well as of the lumps, was found and the particle size tends to a more unimodal distribution, which is typically favoured. At even higher $\mathrm{L} / \mathrm{S}$ ratios, granules were found to become oversized. For batch wet granulation processes, it is well known that the amount of added water is critical. It has been described that the granulation process can be divided into different regimes (formation of nuclei, agglomerate growth, paste formation) depending on the amount of water added.[11] The granulation regime map indicates the amount of water required to form nuclei. By increasing the amount of water being processed, a regime of steady agglomerate growth can be found. Upon further addition of water, a paste is formed. It was found that this description of regimes is also applicable to wet granulation in a continuous twin-screw granulation process. ${ }^{[8,10 b]}$ Despite the link to critical quality attributes, neither quantitative $\mathrm{L} / \mathrm{S}$ ratio boundaries corresponding to these regimes, nor methods to assess these boundaries in a continuous twin-screw wet granulation process are described in the literature.

This study focusses on the technical aspects that can help improving the quality of continuous manufacturing processes. Thereto, L/S ratio boundaries for the granulation regime in twin-screw wet granulation were investigated. Two different quantitative methods to define the granulation regime were investigated; the first method was based on measuring the variation of wet granule mass flow from the granulator outlet. It has been reported that after wetting, powder material starts to stick to a number of surfaces, such as other powder particles, measurement probe heads or other equipment surfaces. It has been hypothesised that the tendency for sticking increases drastically as soon as the material becomes over-wetted. Consequently, the wet granule mass flow is assumed to show a higher fluctuation at the onset of over-wetting, thus indicating the upper $\mathrm{L} / \mathrm{S}$ ratio boundary of the granulation regime. The second method is based on the particle size distribution of the dried granules. It has been described in literature that granules start to grow as soon as enough granulation liquid is added. ${ }^{[10 b]}$ The onset of granule growth is used to indicate the lower L/S ratio boundary. The two methods were used in combination to define the granulation regime in continuous twinscrew wet granulation for some model drug substance formulations, changing the composed excipients. Finally, the impact of the L/S ratio and the resulting granule properties on further downstream processing (tableting) is shown, indicating the further importance of being able to assess the L/S ratio boundaries of the granulation regime quantitatively. This study describes the wet granulation process as an example for a continuous process that involves multiple sequential mechanisms, is fast, intrinsically unstable and irreversible and needs to be held within its L/S ratio boundaries.

\section{Experimental}

\section{Materials}

The materials used for granulation were ibuprofen (Ibuprofen 25, BASF), microcrystalline cellulose (MMC, Vivapur 102, JRS Pharma), lactose monohydrate (Lactose spray dried, Kerry Bio-Science), polyvinylpyrrolidone K30 (Plasdone K-29/32, Ashland) and magnesium stearate (Faci Spa.). Demineralised water has been used as granulation liquid.

\section{Blending}

Ibuprofen (model drug substance) was sieved through a $1 \mathrm{~mm}$ mesh before weighing. The components were blended in a batch size of $3.8 \mathrm{~kg}$ using a turbula blender (Willy A. Bachofen, type T10A) for $5 \mathrm{~min}$ at $25 \mathrm{rpm}$, before sieving again (1 mm mesh size). Formulations are shown in Table 1.

\section{Twin-screw Granulation}

Twin-screw wet granulation was performed in triplicate for each formulation

Table 1. Ibuprofen formulations with different fillers or a combination of fillers.

\begin{tabular}{|l|l|l|l|}
\hline Component & Lactose-based & Lactose-MCC-based & MCC-based \\
\hline Ibuprofen 25 & 60 & 60 & 60 \\
\hline Lactose & 36 & 18 & - \\
\hline MCC & - & 18 & 36 \\
\hline Polyvinylpyrrolidone K30 & & 2.5 & \\
\hline Magnesium stearate & & 1.5 & \\
\hline
\end{tabular}


at each $\mathrm{L} / \mathrm{S}$ ratio in a randomised sequence using a co-rotating twin-screw granulator (Thermo Fisher Scientific, Thermo Scientific Pharma 11) with a screw diameter of $11 \mathrm{~mm}$ and a screw length of $403 / 4 \times \mathrm{D}$, operated at a screw speed of $250 \mathrm{rpm}$. The screw was configured with two kneading zones (first zone $11 / 2 \mathrm{D}$ at $60^{\circ}$ staggering angle, second zone $11 / 4$ $\mathrm{D}$ at $30^{\circ}$ staggering angle) separated by a conveying element and a section of distributive flow elements (4 D) at the screw end (Fig. 1). The temperature in all barrel zones was kept at $20^{\circ} \mathrm{C}$. The powder blend was fed constantly at a mass flow rate of $500 \mathrm{~g} / \mathrm{h}$, using a Brabender gravimetric feeder (Brabender, DDW-MD0-MT-1). The feeder was calibrated using the internal calibration mode. In order to obtain granules manufactured at different L/S ratios, water addition rates were varied, using a progressing cavity pump (Netzsch, NM003BY11S12B). For L/S ratios below 0.15 a syringe pump was used (Faulhaber, Harvard Apparatus B-51312). The wet granule mass flow was monitored from the end of the twin-screw granulator using a dynamic balance (K-Tron, K-Sampler K-SFS-24). The variation in wet granule mass flow was determined by calculating the relative standard deviation of the fivesecond mass increments over a period of ten minutes. After ten minutes processing time, a sample of approximately $5 \mathrm{~g}$ was taken to verify the residual moisture content by using a moisture analyser (HS153, Mettler Toledo). The sample was dried at $105{ }^{\circ} \mathrm{C}$, until the loss in weight was less than $1 \mathrm{mg}$ over 50 seconds.

\section{Drying and Particle Size Distribution}

Wet granules were collected over a 10 minute processing time and dried using a fluid bed dryer (Glatt, Mini-Glatt 5) at an inlet air temperature of $65^{\circ} \mathrm{C}$. The airflow was increased until fluidisation of the powder bed was observed. The size distribution of the dried granules was analysed for every batch once with dynamic image analysis (Retsch Technology, Camsizer XT) using the air-jet module with a dispersion pressure of $30 \mathrm{kPa}$. Results are shown as volume density distributions (q3). The median particle size (x50) was calculated.

\section{Tableting}

$500 \mathrm{mg}$ round flat-faced compacts (11.28 mm diameter) were produced for one batch of each formulation at each L/S ratio using a fully instrumented compaction simulator (Medelpharm, Stylcam 200R) to mimic a Fette P1200 press. Dried granules were sieved through a $1 \mathrm{~mm}$ mesh, before compacts $(n=32)$ were manufactured at a compaction pressure of 100 $\mathrm{MPa}$ and a dwell time of $13 \mathrm{~ms}$. Besides

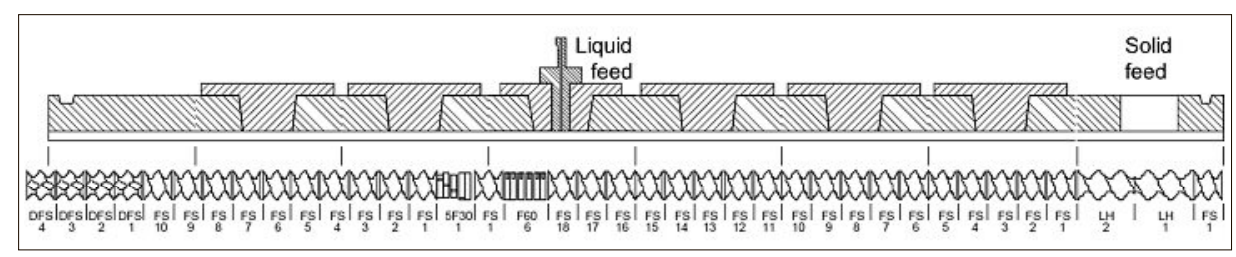

Fig. 1. Configuration of the screw elements. The process direction is from the right to the left.

the comprised lubricant in the formulation, no additional lubrication was applied. The tablet mass was determined.

The tableting compaction process was characterised using the energy profile derived from the force-displacement curve of the upper tableting punch, as described in literature (Fig. 2) ${ }^{[12]}$ It has been described, that $\mathrm{E}_{\text {total }}\left(\mathrm{E}_{\text {total }}=\mathrm{E} 1+\mathrm{E} 2+\mathrm{E} 3\right)$ is the energy consumed during one tablet compaction cycle. E1 represents the energy loss during one compaction cycle due to various effects. In literature, the energy loss E1, for example, is related to machine friction, powder particle rearrangement and particle breakages. E2 represents the final work of compaction, whereas E3 represents the elastic recovery after removal of the compaction force. The compaction energies were recorded by the tableting machine and used for calculating an indicator, which can be applied for characterising the tableting compaction process. The calculated indicator, the $\mathrm{E} 2 / \mathrm{E}_{\text {total }}$ ratio, represents the ratio of the energy, which is applied to the powder bed and transformed into the formation of bindings in the compact, and the total energy, which is consumed during one tablet compaction cycle. This ratio is for example impacted by the granule size distribution. A high value could indicate an appropriate granule size distribution with a suitable powder flow and density for tableting.

\section{Results and Discussion}

In a first step, two different quantitative methods were investigated to determine whether they could be used to define the $\mathrm{L} / \mathrm{S}$ ratio boundaries of the granulation regime. The first method was based on the assumption that the mass flow variation would significantly increase once a paste was being formed, thereby indicating over-wetting of the product. The second method measures the onset of granule formation by measuring the size of the granulated powder after drying. Granulation is initiated after a minimum water addition level which can be seen from the particle size distribution plots.

Typically, quantitative boundaries of the L/S ratio granulation regime are determined by torque measures in high shear wet granulation. ${ }^{[13]}$ With increasing water addition level, the impeller torque increases which in turn correlates reasonably well with changes in the granulation size distribution. ${ }^{[14]}$ In twin-screw wet granulation, correlations of torque and granule size distribution often are unreasonable, due to dispensable changes in torque with increasing $\mathrm{L} / \mathrm{S}$ ratio. The $\mathrm{L} / \mathrm{S}$ ratio granulation regime is typically determined visually by the operator. The visual inspection of the powder at low $\mathrm{L} / \mathrm{S}$ ratios can be used to determine that no granulation was initiated (Fig. 3). Upon increasing the L/S ratio, granule growth was seen. At even higher L/S ra-

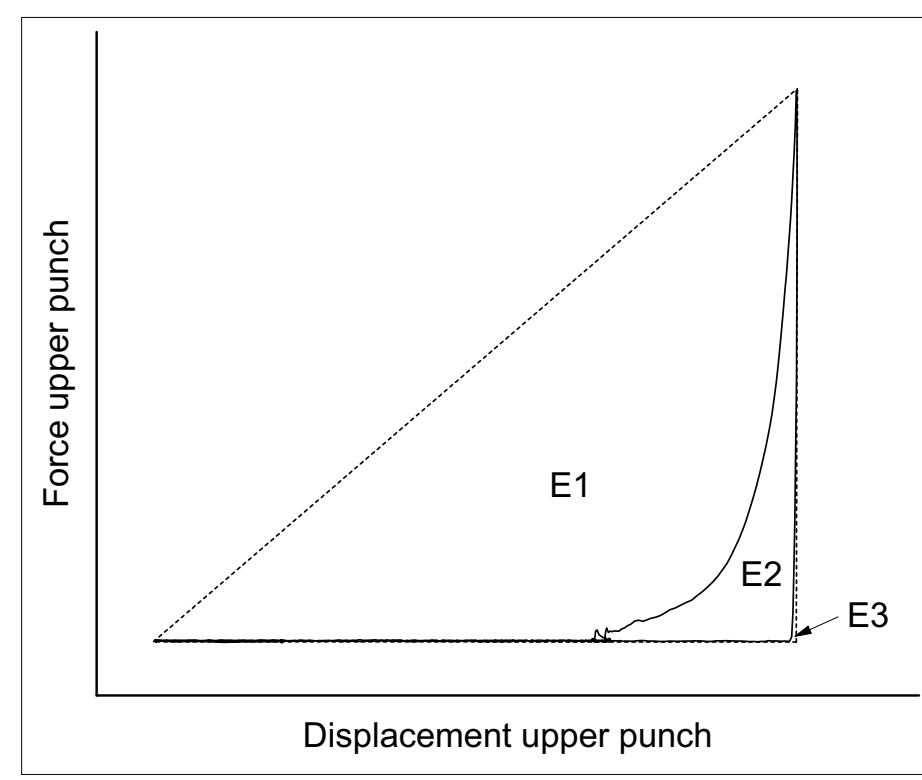

Fig. 2. Example for the MCC-based formulation: The force-displacement curve including the different energies E1-E3, which are used to characterise the tablet compaction process. 


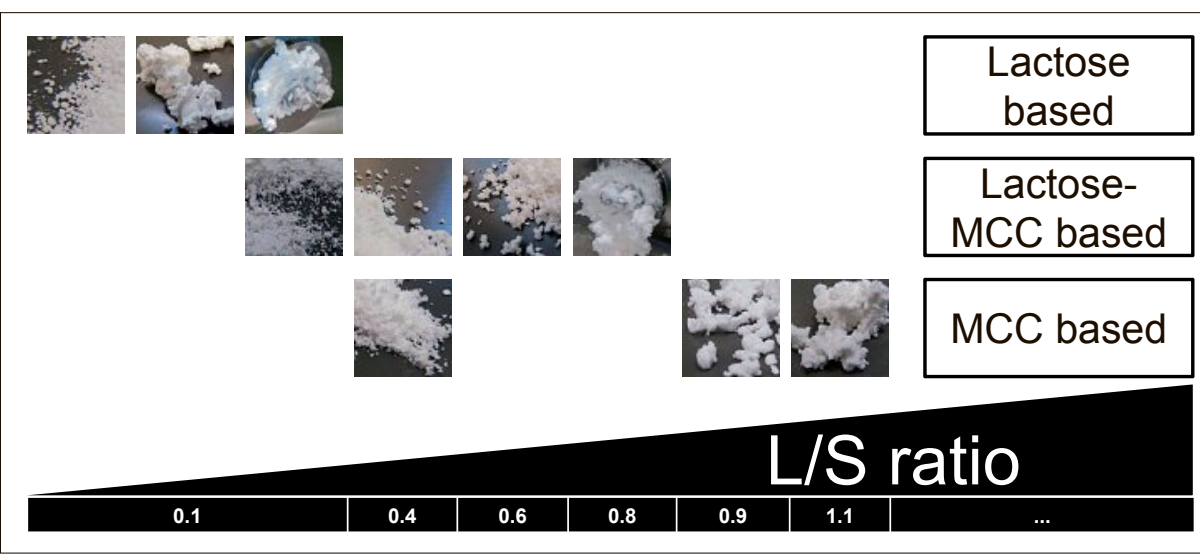

Fig. 3. Visual findings of the twin-screw granulation behaviour of a lactose-based, lactose-MCCbased and MCC-based ibuprofen formulation with increasing L/S ratios. Formulations showed no granulation, granule growth and formation of paste at and within different L/S ratio ranges.

tios, the wet granule mass was over-wetted and a paste formed. These findings agree well with the literature. ${ }^{[10 b]}$ Moreover, this shows that the process should be investigated between the $\mathrm{L} / \mathrm{S}$ ratio at which first granule growth is observed and the L/S ratio at which a paste is formed.

It was also found that different formulations require different L/S ratio granulation regimes. In the case of the lactose-based formulation for example, the visual findings of no granulation, granule growth and paste formation were made within a relatively narrow range of low $\mathrm{L} / \mathrm{S}$ ratios $(0.10$ to 0.13 ). In addition it was seen that granule properties for this formulation were sensitive to small changes in the $\mathrm{L} / \mathrm{S}$ ratio. By contrast, the MCC-based formulation required a higher water addition level for the onset of granule growth, and had a wider granulation regime. Although this may be seen as intuitive, it does exemplify the need for a quantitative method to define the process window.

The upper boundary of the L/S ratio dependent granulation regime was assessed by determining the wet granule mass flow variation of the twin-screw granulator as function of the L/S ratio. Up to the L/S ratio where the onset of over-wetting (indicated by the formation of a paste) of granules was observed, a continuous consistent wet granule mass flow was observed (Fig. 4a). At higher L/S ratios it was seen that

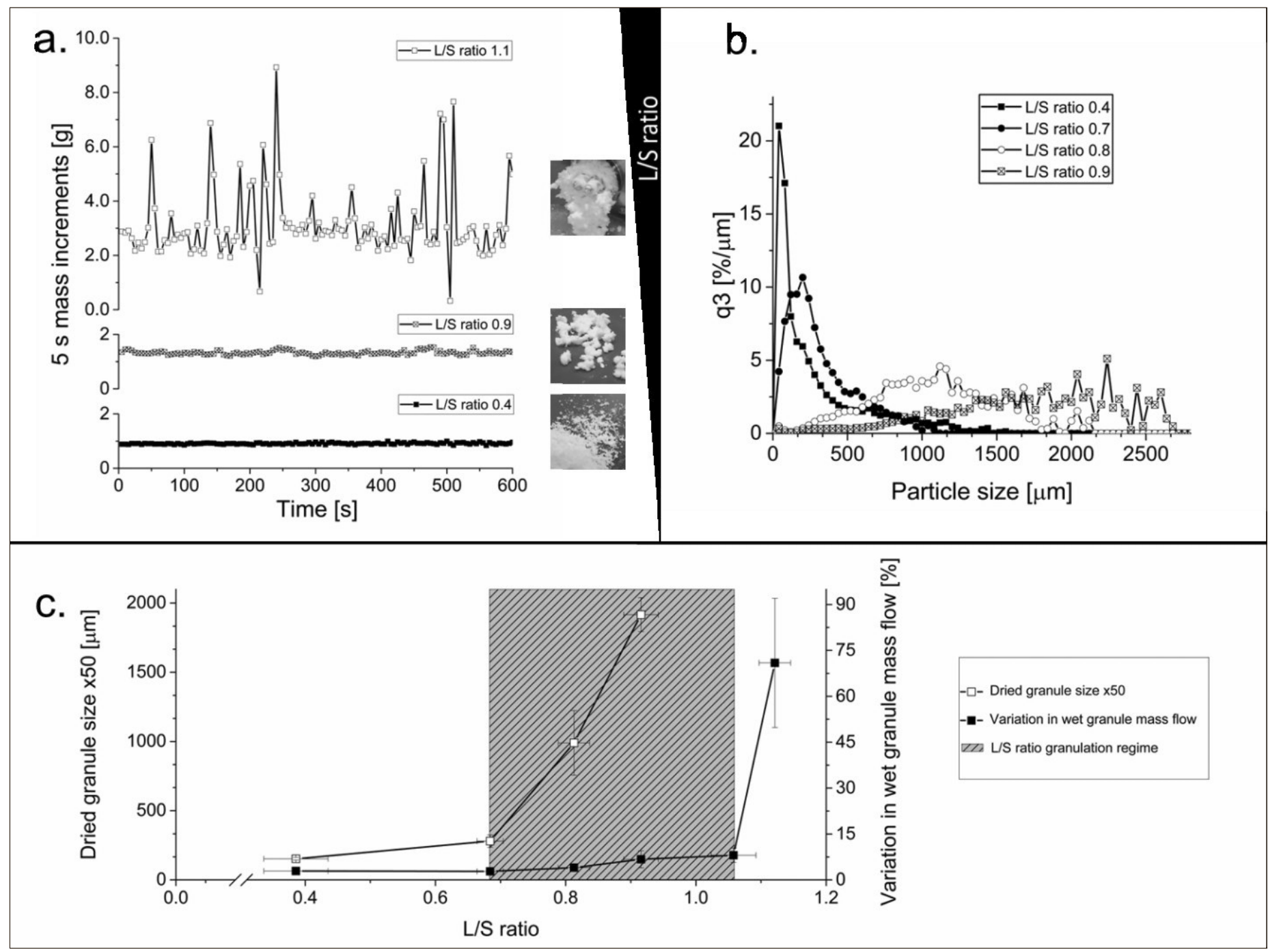

Fig. 4. Data recorded for the MCC-based formulation: a. The wet granule mass flow at the outlet of the twin-screw granulator is shown for increasing $\mathrm{L} / \mathrm{S}$ ratios and the corresponding visual appearance (data shown for $\mathrm{n}=1$ for illustration purposes). $\mathrm{b}$. The volume-based dry-granule size distribution is shown for various L/S ratios. With increasing L/S ratios, a broader span was seen, and the distribution was shifted to coarser granule sizes (data shown for $\mathrm{n}=1$ for illustration purposes). c. The variation in wet granule mass flow and dried granule size $\mathrm{x} 50$ were combined to indicate the granulation regime (average \pm standard deviation; $n=3$ ). 
material started to stick and to accumulate on metal surfaces of the twin-screw granulator. This phenomenon was seen most strongly at the twin-screw granulator outlet. The relative standard deviation (RSD) was found to increase. For the MCC-based formulation, for example, the averaged relative standard deviation increased from $3 \%$ at an $\mathrm{L} / \mathrm{S}$ ratio of 0.39 , to $7 \%$ at an $\mathrm{L} / \mathrm{S}$ of 0.92 and to $71 \%$ at an $\mathrm{L} / \mathrm{S}$ ratio of 1.12 .

The lower boundary of the L/S ratio dependent granulation regime was assessed by determining the dried granule size as function of the L/S ratio. With increasing $\mathrm{L} / \mathrm{S}$ ratio, the volume-based granule particle size distribution (q3) showed a reduction in the fraction of fines and an increase of the fraction of coarse granules (Fig. 4b). Consequently, the granule size indicator x 50 (which corresponds to $50 \%$ of the particles smaller than the given size based on their volume distribution) increased with increasing L/S ratios. For the MCC-based formulation, for example, the averaged $\mathrm{x} 50$ of the dried granule size increased from $153 \mu \mathrm{m}$ at an L/S ratio of 0.39 , to $281 \mu \mathrm{m}$ at an L/S ratio of 0.68 and to 1916 $\mu \mathrm{m}$ at an L/S ratio of 0.92 .

Finally, to define the L/S ratio dependent granulation regime, results of both quantitative methods were used in combination (Fig. 4c). The upper boundary was set at the onset of over-wetting. For L/S ratios below the onset of over-wetting, the gradient of the variation in the wet granule mass flow as function of the L/S ratio was consistently low. At the onset of over-wetting, a sharp increase in the gradient was found. The lower boundary was set at the onset of granule growth as measured from the dry granules. Below the L/S ratio where the onset of dried granule growth was observed, the $\times 50$ of the dried granule size was increasing slightly. Above this L/S ratio, particle surfaces were wetted sufficiently to initiate granule growth. At the onset of granulation, a change in the gradient of the $\mathrm{x} 50$ of the dried granule size as function of the $\mathrm{L} / \mathrm{S}$ ratio was observed as a threshold and used to define the lower L/S ratio boundary of the granulation regime. By using the two methods in combination, the upper L/S ratio boundary for the granulation regime was shown to be around 1.1, whereas the lower boundary for the granulation regime was shown around an $\mathrm{L} / \mathrm{S}$ ratio of 0.7 for the MCC- based formulation. Thus the granulation regime for the MCCbased formulation can be found between the L/S ratios 0.7 and 1.1. However, since the granule size constantly increases with increasing $\mathrm{L} / \mathrm{S}$ ratio in the granulation regime and large granules may require an additional process step before tableting, such as milling, preferably the twin-screw wet granulation process should be performed at the lower side of the granulation regime.

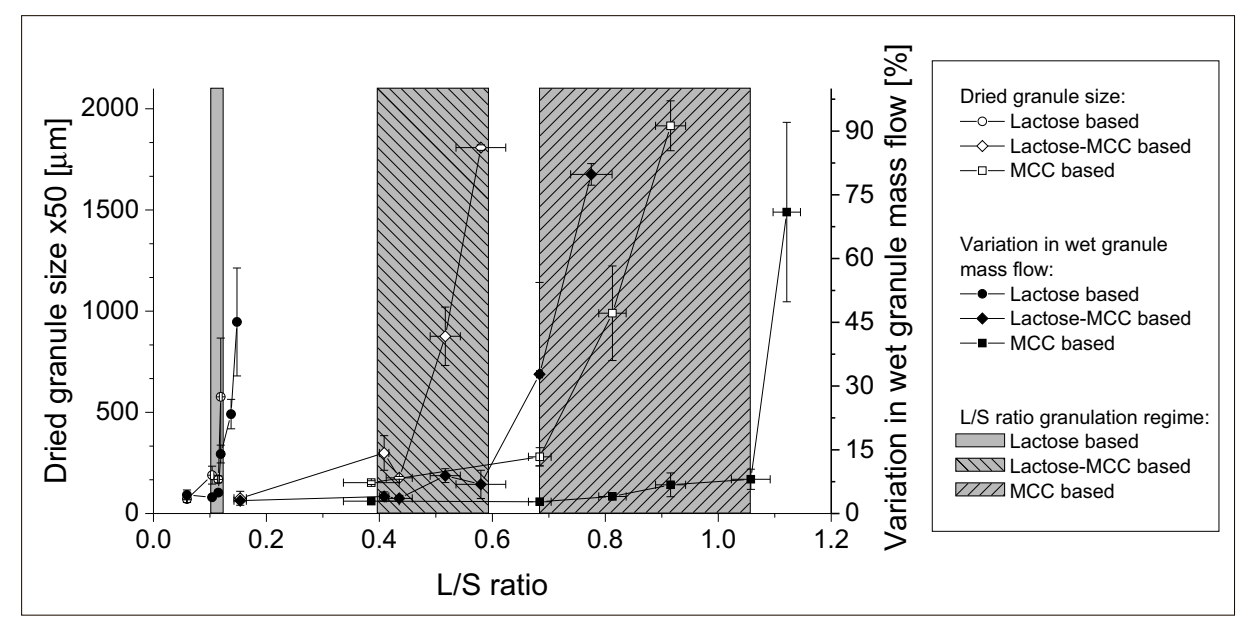

Fig. 5. Granulation regimes of a lactose-based, lactose-MCC-based and MCC-based formulation. The granulation regimes differ significantly in their range and in the spread of L/S ratios. (average \pm standard deviation; $n=3$ )
Using the investigated methods, the impact of different formulations (based on different fillers) on the granulation regime was investigated. In this study, each formulation contained $60 \% \mathrm{w} / \mathrm{w}$ of the model drug substance ibuprofen. This is considered to be a fairly high drug load, resulting in limited filler amounts in the formulation. These formulations can therefore be considered a 'worst case' with respect to improving processability via formulation optimisation. Despite the relatively small amount of fillers used in the formulation, a significant impact on the granulation regime was seen (Fig. 5). The lactose-based formulation showed a narrow regime at a low range of $\mathrm{L} / \mathrm{S}$ ratios in comparison to an MCC-based formulation. For the lactose-based formulation, the granulation regime was found to be between 0.10 and
0.13 , while for MCC it was between 0.7 and $1.1 ;$ i.e. the twin-screw wet granulation process using MCC as filler in the formulation showed a comparable granulation process to the lactose-based formulation, but the granulation regime was observed over a broader range of $\mathrm{L} / \mathrm{S}$ ratios. This results in the granulation process being less sensitive to changes in the L/S ratio. Finally, lactose and MCC were combined as fillers in similar ratios. For this formulation the granulation regime was of a range in between that of the formulations based on either one of these fillers, i.e. 0.4 to 0.6.

The quantitative assessment was found to be applicable for all the investigated formulations. Moreover, it was indicated that the twin-screw wet granulation process could be significantly optimised. It was shown that by using the quantitative assess-

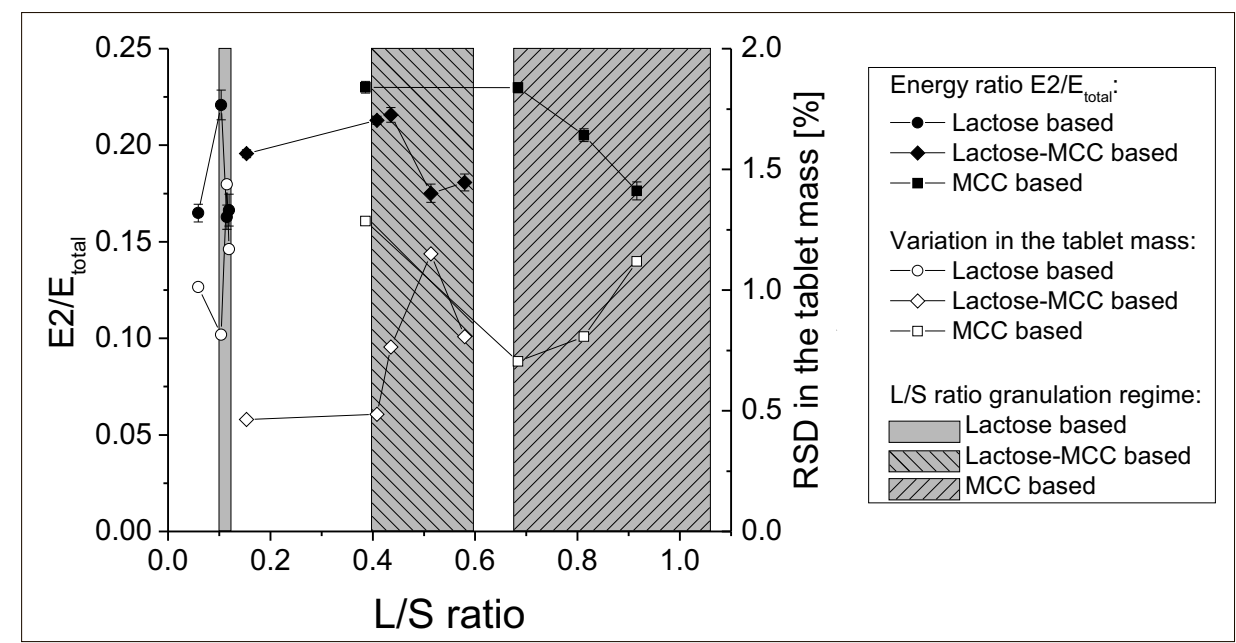

Fig. 6. Application of the granulation regime in twin-screw wet granulation to the tableting process. The optimal $\mathrm{E} 2 / \mathrm{E}_{\text {total }}$ ratio and tablet mass variation at the same time were shown for batches, granulated at the lower side of the granulation regime. Batches granulated at lower L/S ratios, outside the regime, were indicated undergranulated with decreased $\mathrm{E} 2 / \mathrm{E}_{\text {total }}$ ratio and/or poorer fill of the tablet die. Batches granulated at higher $L / S$ ratios within the regime also showed a lower $E 2 / E_{\text {total }}$ ratio and higher tablet mass variation. However, these granules could be further processed, by implementing a milling step. $\left(E 2 / E_{\text {total }}\right.$ : average \pm standard deviation; $n=32 ; R S D$ in tablet mass based on 32 tablets) 
ment, the relationship of the dried granule size and the L/S ratio could be adapted via the formulation (i.e. granule growth at low/ high $\mathrm{L} / \mathrm{S}$ ratios, over a narrow/broad range of $\mathrm{L} / \mathrm{S}$ ratios). If the formulation would be designed to achieve a broad granulation regime for example, the impact of potential fluctuations in the liquid and/or solid mass flow rates on the critical quality attributes of the product would be less pronounced leading to improved robustness of the continuous twin-screw wet granulation process. For example, in this study the lactose-based formulation exhibited a narrow granulation regime. Replacing a portion of the lactose with MCC allowed the granulation regime to be broadened by approximately a factor of 6 . This has the effect that the formulation containing a mixture of lactose and MCC would tolerate much larger fluctuations in $\mathrm{L} / \mathrm{S}$ ratio than the lactose-based formulation before the same variation in dried granule size would be observed. These quantitative findings agree with visual observations. Although the granulation regime could be broadened further by replacing all lactose in the lactose-based formulation with MCC, this would be detrimental to the downstream processes. For example, since the granulation regime of the MCC-based formulation compared to the lactose-based formulation is not only broadened, but also shifted towards higher L/S ratio, the wet granules contain more moisture, which would then require a higher capacity during the drying step.

Another downstream process impacted by the granule quality is the tableting process. In a tableting process, generally speaking, good powder flow properties and a suitable powder density are required to achieve an even and consistent filling of the tablet die and hence less variation in the tablet mass and hardness. A suitable granule size distribution is one of the prerequisites for a stable tableting process and thereby a high drug product quality. Although tableting is at least two unit operations downstream from the continuous twin-screw wet granulation operation, the value of establishing the L/S ratio granulation regime using the mass flow variation and granule size distribution was also demonstrated. It has been reported in literature that the use of the $\mathrm{E} 2 / \mathrm{E}_{\text {total }}$ ratio as an indicator is one way to characterise a tablet compaction process of granules. ${ }^{[12]}$ The $\mathrm{E} 2 / \mathrm{E}_{\text {total }}$ ratio is shown as function of the $\mathrm{L} / \mathrm{S}$ ratio for all three formulations together with the observed tablet mass variation (Fig. 6). A high value for the ratio and a low tablet mass variation are favoured and indicate good tableting characteristics.

A comparable trend was observed for all formulations: An optimum for the E2/ $\mathrm{E}_{\text {total }}$ ratio and the tablet mass variation at the same time were shown for batches granulated at the lower side of the granulation regime (for example, an $\mathrm{E} 2 / \mathrm{E}_{\text {to }}$ ratio of 0.22 and a variability of only $0.82 \%$ for the lactose-based formulation granulated at an L/S ratio of 0.10) (Fig. 6). Under these conditions, sufficiently large granules were formed to improve the powder flow into the tablet die and to have an optimal density to minimise random air entrapment. For batches granulated at L/S ratios below the granulation regime, for the lactose- and MCC-based formulation, the tablet variation increased, whereas the $\mathrm{E} 2 / \mathrm{E}_{\text {total }}$ decreased, at least slightly, for the lactose and lactose-MCC formulation indicating less favourable tableting properties. Although in some specific examples the changes are relatively small, this confirms that the powder particles were undergranulated, meaning that there was insufficient particle enlargement, resulting in a suboptimal powder flow from the hopper into the tablet die. Furthermore, the small particles lead to less dense powder packing. For formulations composing lactose, the energy consumption for the consolidation of the less dense powder bed was increased and in turn resulted in a lower $\mathrm{E} 2 / \mathrm{E}_{\text {total }}$ ratio. For batches granulated at higher L/S ratios, but within the granulation regime, a decreasing $\mathrm{E} 2 / \mathrm{E}_{\text {total }}$ ratio was observed. Although the powder flow further improves with increasing granule size, the powder fill density in the die decreases. Large granule particles tend to result in less dense powder packing, due to air entrapment between the particles. The energy to consolidate the powder bed before compaction increases and the E2/ $\mathrm{E}_{\text {total }}$ ratio decreases. For batches granulated at $\mathrm{L} / \mathrm{S}$ ratios above the upper limit of the granulation regime an unprocessable paste was formed that could not be properly assessed in a tableting process.

Although the above data suggest a more narrow process window at the lower side of the granulation regime, granules produced at higher $\mathrm{L} / \mathrm{S}$ ratios within the granulation regime can be successfully processed. In pharmaceutical processing, it is common to implement a milling step after the drying step. This would then ensure that all granules from within the granulation regime could be processed. However, if the granules outside the regime are tested, they would be either too small or paste-like, such that further processing would not be possible.

\section{Conclusions}

As an example for a continuous process that involves multiple sequential mechanisms, is fast, intrinsically unstable and irreversible, a wet granulation process in a twin-screw granulator has been investi- gated. This study has shown that the wet granule mass flow variation and the granule size distribution are useful tools in establishing an L/S ratio granulation regime for continuous twin-screw wet granulation. The applicability of the quantitative assessment of the L/S ratio granulation regime was shown for formulations comprising different fillers and a combination of fillers. It was shown that the formulation has a significant impact on the L/S ratio boundaries of the granulation regime in twin-screw wet granulation. Finally, it has been demonstrated in this example, that robustness and performance of twin-screw wet granulation processes and following downstream processes, such as drying or tableting, can be optimised by using the quantitative assessment. Even though the processing time is short, the continuous process thereby can be controlled well.

Received: July 14, 2016

[1] H. Leuenberger, Eur. J. Pharm. Biopharm. 2001, 52, 289.

[2] K. Plumb, Chem. Eng. Res. Des. 2005, 83, 730

[3] a) S. Byrn, M. Futran, H. Thomas, E. Jayjock, N. Maron, R. F. Meyer, A. S. Myerson, M. P. Thien, B. L. Trout, J. Pharm. Sci. 2015, 104, 792; b) K. Nepveux, J. P. Sherlock, M. Futran, M. Thien, M. Krumme, J. Pharm. Sci. 2015 , 104, 850; c) J. S. Srai, C. Badman, M. Krumme, M. Futran, C. Johnston, J. Pharm. Sci. 2015, 104, 840; d) G. Allison, Y. T. Cain, C. Cooney, T. Garcia, T. G. Bizjak, O. Holte, N. Jagota, B. Komas, E. Korakianiti, D. Kourti, J. Pharm. Sci. 2015, 104, 803.

[4] L. Malet-Sanz, F. Susanne, J. Med. Chem. 2012, $55,4062$.

[5] M. Fonteyne, J. Vercruysse, F. De Leersnyder, B. Van Snick, C. Vervaet, J. P. Remon, T. De Beer, Trends Anal. Chem. 2015, 67, 159.

[6] a) S. D. Schaber, D. I. Gerogiorgis, R Ramachandran, J. M. B. Evans, P. I. Barton, B. L. Trout, Ind. Eng. Chem. Res. 2011, 50, 10083; b) D. Djuric, P. Kleinebudde, Pharm. Dev. Technol. 2010, 15, 518 .

[7] G. S. Calabrese, S. Pissavini, AIChE J. 2011, 57, 828 .

[8] E. I. Keleb, A. Vermeire, C. Vervaet, J. P. Remon, Int. J. Pharm. 2004, 273, 183.

[9] a) R. Meier, M. Thommes, N. Rasenack, M Krumme, K.-P. Moll, P. Kleinebudde, Int. J. Pharm. 2015, 496, 12; b) J. Vercruysse, D. Córdoba Díaz, E. Peeters, M. Fonteyne, U. Delaet, I. Van Assche, T. De Beer, J. P. Remon, C. Vervaet, Eur. J. Pharm. Biopharm. 2012, 82, 205; c) R. M. Dhenge, J. J. Cartwright, D. G. Doughty, M. J. Hounslow, A. D. Salman, $A d v$. Powder Technol. 2011, 22, 162; d) T. C. Seem, N. A. Rowson, A. Ingram, Z. Huang, S. Yu, M. de Matas, I. Gabbott, G. K. Reynolds, Powder Technol. 2015, 276, 89.

[10] a) R. M. Dhenge, J. J. Cartwright, M. J. Hounslow, A. D. Salman, Powder Technol. 2012 229, 126; b) A. El Hagrasy, J. Hennenkamp, M. Burke, J. Cartwright, J. Litster, Powder Technol. 2013, 238, 108.

[11] S. Iveson, J. Litster, AIChE J. 1998, 44, 1510.

[12] M. Dürr, D. Hanssen, H. Harwalik, Pharm. Ind. 1972, 34, 905 .

[13] H. Leuenberger, Eur. J. Pharm. Biopharm. 2001, 52, 279.

[14] M. B. Mackaplow, L. A. Rosen, J. N. Michaels, Powder Technol. 2000, 108, 32 